\title{
Life Cycle Cost, As a Tool for Decision Making on Concrete Infrastructures
}

\author{
José Matos $^{1(\bowtie)}$, Anders Solgaard ${ }^{2}$, Carlos Santos ${ }^{1}$, \\ Mauricio Sanchez Silva ${ }^{3}$, Poul Linneberg ${ }^{2}$, Alfred Strauss ${ }^{4}$, \\ Joan Casas ${ }^{5}$, Colin Caprani ${ }^{6}$, and Mitsuyoshi Akiyama ${ }^{7}$ \\ 1 Department of Civil Engineering, Engineering School, University of Minho, \\ Campus de Azurém, 4800-058 Guimarães, Portugal \\ jmatos@civil.uminho.pt \\ 2 COWI A/S, Parallelvej 2, 2800 Kongens Lyngby, Denmark \\ 3 Department of Civil and Environmental Engineering, \\ Geomaterials and Infrastructure Systems Group, Universidad de Los Andes, \\ Carrera 1 Este N. 19A-40 Edificio Mario Laserna, \\ Off. ML630, Bogotá, Colombia \\ ${ }^{4}$ Institute of Structural Engineering (IKI), BOKU, \\ Peter-Jordan-Straße 82, 1190 Vienna, Austria \\ 5 Department of Construction Engineering, \\ Technical University of Catalonia - BarcelonaTech, \\ Jordi Girona 1-3 Campus Nord Modul C1, 08034 Barcelona, Spain \\ ${ }^{6}$ Department of Civil Engineering, Monash University, \\ 23 College Walk (Bld 60), Clayton Campus, Melbourne, Australia \\ 7 Department of Civil and Environmental Engineering, Waseda University, \\ Building 51-16-09, 3-4-1 Okubo, Shinjuku-Ku, Tokyo 169-8555, Japan
}

\begin{abstract}
The use of Life Cycle Cost (LCC) tools in civil engineering is increasing, due to the need of infrastructure owners and operators to guarantee their assets maximum performance with an optimized budget. By considering these tools it will be possible to manage assets along their lifetime in a more sustainable and efficient way. Due to this reason, it was recently constituted a Task Group on $f i b$ to deal with existing LCC tools for concrete infrastructures. This paper gives an introduction to these tools, with a special emphasis to the added-value of LCC, and to the main contents of the fib TG 8.4 state-of-art technical report. This covers a description of existing LCC standards and guidelines, their applicability, the definition of different cost elements, the incorporation of risk in the analysis, etc.
\end{abstract}

Keywords: Life Cycle Cost (LCC) - Concrete structures - Framework

\section{Introduction}

The recently constituted fib Task Group 8.4 on existing LCC tools for concrete infrastructures, has the aim of presenting the LCC framework and some applications in concrete structures. A fib bulletin, state of art technical report on LCC applications to concrete structures, will be the main deliverable of this Task Group. At this point, the 
bulletin structure is fixed, respectively: Section 1 Introduction and General Background; Section 3 Existing LCC standards, guidelines and software; Section 4 Methodology of LCC analysis; Section 5 Cost elements in LCC models; Section 5 Uncertainties, reliability and risk; Section 6. Case studies. The aim of this paper is to present an overview of the on-going works for the bulletin preparation with the identification of the most important LCC topics, which are its added value, existing standards and guidelines, the methodology, how to incorporate risk, and finally some of the selected case studies.

\section{Added Value of LCC}

In large infrastructure projects (bridges, highways, ports, airports, etc.), one or few actors carry the burden of not only the initial investment but also of the maintenance and operation, which puts a lot of pressure on the decisions throughout the projects lifetime. Thus, in order to improve the long-term decision making it is important to shift the focus of funding toward system preservation and look at both up-front and long-term costs to ensure sustainability of future budgets and better management of infrastructure. Within this context, the life cycle cost analysis (LCCA) plays a significant role in modern engineering project management.

Traditionally, construction project procurement was undertaken without further consideration as to the costs, which would be incurred from construction to disposal; this approach focused mainly on finding the cheapest technically feasible alternative. On the contrary, modern engineering focuses on the balance between value and risk of quality and price. Within the field of large infrastructure management, owners have an obligation to ensure the project is maintained at an acceptable standard throughout their lifetime. As infrastructure projects are long-term assets, not having an integrated and long-term plan for regular operation may considerably affect the returns on investment (Ellingham and Fawcett 2006).

The aspects where LCC analysis has its major impact over traditional design are classified as follows:

- System operation and project development: it allows involving activities as operation policies (inspection, interventions, monitoring, etc.); economic exploitation (improvement service, charge strategy, financial strategies, etc.) and future developments (expansion, technology update, etc.);

- Cost structure of projects: It provides a decision making framework that it allows to assess the overall costs of a project to select the design and management requirements (Rackwitz 2000);

- Sustainability implications: Pollution control, rational use of resources and financial feasibility of engineering projects.

Along lifetime projects are changing entities for which predictions are highly inaccurate and there is a need for permanent decision updating strategies. Thus, LCC analysis can be implemented in different aspects such as: 
- Help to select the best alternative to meet a project objective;

- Evaluate a design requirement within a specified project;

- Compare overall costs between different types of projects;

- Calculate the most cost-effective approaches to project implementation;

- Improve the competitiveness of the construction industry.

The advantages regarding the use LCC analysis are as follow:

- Encourages businesses to find a correct balance between investment costs and operating expenses;

- Enables investment options to be more effectively evaluated;

- Considers the impact of all costs rather than only initial capital costs;

- Facilitates choice between competing alternatives;

- Considers environmental impact and sustainability of construction.

It is should be noted that the tools and resources for conducting and performing LCC analysis exists, and what it is needed to expand its adoption are incentives, legislations and introducing performance evaluation into the planning process.

\section{Existing LCC Standards and Guidelines}

LCC analyses are typically considered in parallel with other analyses related to safety, service (e.g. availability), sustainability (incl. Life Cycle Assessment) etc. Fully integration of these analyses calls for multi-criteria analyses because of difficulties in monetization of all impacts.

LCC analyses are typically based on net present values, where a discount rate is used to convert cash flows occurring at different time to a common time, to reflect the time value of money. The discount rate has a significant impact on the final result of LCC analyses and hence the selection of a suitable discount rate is crucial for the decision-making (ISO 15686-5 2008; Linneberg et al. 2014).

LCC may be carried out as part of feasibility studies to find the most cost-efficient solution, as part of a detailed design to determine an in-service budget for the owner, as part of the tender to evaluate the most attractive bid proposal, or as part of the operation to evaluate the optimum operation and maintenance strategy. Within asset management, the latter analysis is often referred to as improved financial performance (ISO 55000 2014).

Regarding LCC standards, some are purely generic (e.g. EN 60300-3-3 2005) while others are (semi) asset specific (e.g. EN 15643-4 2012; ISO 15686-5 2008; and ASTM E917-05 2010). A vast amount of guidelines and handbooks, also dealing with LCC, has been published. Especially, fib Bulletin 71 (2013) on integrated life cycle assessment of concrete structures, is a very interesting report covering several issues related to LCC. Some guidelines are asset specific such as FHWA-NJ-2003-012 (2003); FHWA-IF-02-0047 (2002) and SAMPT (2015), relevant for infrastructure assets, while others are generic, e.g. The Green Book (2011).

A number of software packages exist for LCC analyses - some are tailor made for a specific asset, others are generic - being merely a tool that may be used for LCC 
analyses. An application of some LCC analysis software can be seen in MAINLINE (2013), dealing with infrastructure assets regarding an overview of available software packages.

The engineering community within concrete structures moves toward performance based design and management. Both topics require treatment of uncertainties, which motivates adoption of risk and reliability based approaches. Reference for further information is made to the state-of-the-art collection on risk-based lifecycle performance of structural systems compiled in Journal of Structural Engineering, vol. 142 (9), 2016.

\section{LCC Analysis Methodology}

LCC goes beyond the traditional idea that the central element in design is the physical (mechanical) behavior of the system (e.g., structure). This means that financial factors (e.g. cost of future investments, discount rates, etc.), inter-generational responsibility, environmental aspects and sustainability, among others, become relevant elements in the analysis and the definition of the project characteristics. There are three forces driving the evolution and use of LCC during the last decade: (1) government regulations all over the world are moving in the direction of life cycle "accountability"; (2) businesses of all sorts have recognized that LCC is the key to fostering efficiency and continuous improvement; and (3) continuous and long-term environmental protection has emerged as a criterion in both consumer markets and government procurement guidelines.

Thus, LCC has emerged as a valuable decision-support tool for both policy makers and industry in assessing the lifetime impacts of a product or process. From the traditional infrastructure engineering perspective, LCC has been used mainly to obtain design parameters and to define maintenance strategies. Therefore, there is still a need for large engineering projects, especially civil infrastructure, to better integrate with their context and to participate more actively in sustainability development. LCC is the total discounted monetary cost of owning, operating, maintaining, and disposing of a building, building system or infrastructure over a period of time. LCC analysis can be used to evaluate and compare different $M R \& R$ (maintenance, repair and rehabilitation) methods, the calculations are made over the whole service life of a building or a structure and the relevant costs are converted to their equivalent present value (net present value). The alternative with the lowest total present value is the most economical choice.

Different methodologies can be observed for the calculation of LCC. In this sense, Davis Langdon carried out during 2006-2007 an analysis and evaluation of the different national approaches to LCC and developed an EU-wide methodological framework for the estimation of life cycle costs for buildings and constructed assets (Ellingham and Fawcett 2006). As part of the work, they elaborated guidance on how to make cost estimates at each stage of a construction project, from the initial appraisal to the completion and post-occupation phases, including the disposal of the asset. A number of concrete case studies were undertaken to illustrate the practical implementation of this EU-wide approach. One conclusion of this study is that the variety of 
uses of LCC in practice means that it is very difficult to specify a single approach and therefore no single, prescriptive approach to LCC in the current European marketplace is feasible.

The study recognizes that a common methodology needs to be applicable not only to different periods of time over the life cycle of a constructed asset, but also at various points in the life of the asset. Users may adopt an approach to LCC at the inception stage, at the design stage, at the stage of bidding for a construction contract, at the commencement of construction, at the beginning of an O\&M service contract, at the beginning of a warranty period, etc.

In practice LCC is used for a wide range of analysis periods, and the corresponding methodology for LCC analysis needs to accommodate such variety which may include the life cycle (cradle to grave) from inception to disposal of a construction asset, and may also include the period of a long-term service contract (e.g. 25-30 years), or a pre-determined period relating to the client's/user's interest in the constructed asset under consideration. This could include periods covering design, construction and short-term operation, for example, or be restricted to periods that include only the maintenance and replacement (adaptation) of major components. It could also cover the period of Facilities Management (FM) or Public Private Partnership (PPP) contracts.

The following steps can be identified as general in any method of LCC analysis: (1) definition of the project objective and scope; (2) definition of minimum performance requirements and restrictions; (3) identification of alternative options; (3) establishment of analysis assumptions and parameters; (4) building a LCC model; (5) building a cost and time data base; and (6) performing a LCC evaluation.

\section{Uncertainties, Reliability and Risk}

Although perhaps the most obvious, the structural uncertainties (load and capacity) are not the only ones affecting LCC. Accordingly, it is known that both intrinsic (aleatory) and modelling (epistemic) uncertainties affect LCC. Failure cost uncertainty, as well as more general cost uncertainty, should be factored into the general structural risk and reliability problem.

Throughout the lifetime of a concrete structure, there is an inherent risk in its failure (according to some limit state), alongside which there are the costs of such failures, should they occur. Generally, we consider that a financial risk is the probability of a failure event times the cost of its consequences. Obviously then, this risk cost should be factored into the consideration of LCC, since they can be a significant component affecting decision making about the management of the asset (e.g. for the avoidance of costly failures). Further, as the structure ages, this balance of risk and reliability alters (time-dependent effects), and this must also be considered in achieving an overall LCC estimate. With these factors in mind, the background for assessing risk and reliability as they should contribute to an LCC are identified.

The uncertainties are generally classified as resistance variables (e.g. concrete strength), regular-usage load variables (e.g. traffic loads), hazards (e.g. earthquake), and cost variables (e.g. labour), see Table 1. A background on the appropriate statistical modelling of many forms of these variables will be given, based on literature from 
Table 1. Aleatoric parameters

\begin{tabular}{l|l|l|l}
\hline Resistance & Loads & Hazards & Cost elements \\
\hline Concrete strength & Self-weight & Earthquake & Construction \\
\hline Geometry & Building live loads & Blast & Inspection \\
\hline Reinforcement & Highway traffic & Impact & Maintenance \\
\hline Pre-stress strands & Railway & Fire & Repairs \\
\hline Creep and shrinkage & Pedestrian loads & Tsunami & Human loss/injury \\
\hline Corrosion & Wind loads & Overload & Property damage \\
\hline & Snow & & Disruption \\
& Earth pressures & & Environmental \\
& & & Social/political \\
\hline & & & \\
\hline
\end{tabular}

around 60 references. Methods of combining simultaneously acting loads will be explained (e.g. Turkstra's Rule, Ferry-Borges Castanheta rule, and Wen's load coincidence method).

Having summarized the modelling and the uncertain variables in an LCC, it is described some of the risk-based software that is suitable to address the problem, and inform readers on how to input/leverage existing tools to accommodate the models pretended. Essentially, it terminates with an explanation for the readers of putting the discussion into practice.

\section{Case Study}

Based on the concept, procedure, and flowchart of LCC analysis of concrete structures presented in previous sections, three papers are introduced herein (Val and Stewart 2003; Tesfamariam et al. 2013; Safi et al. 2015). To obtain the best balance of the safety, economy and sustainability requirements, LCC estimation of structure and infrastructure must be included in the decision-making process. In recognition of the need for such methods and models, the aim of this section is to present applications and case studies written by experts on the advanced technologies for estimating the LCC of structures such as buildings and bridges, considering, in some situations, the risk.

Val and Stewart (2003) presents a time-variant probabilistic model to predict expected costs of repair and replacement which was used to calculate LCC for RC structures in marine environments under different exposure conditions. Results of the LCC analysis can be applied to select optimal strategies improving durability of RC structures in marine environments.

Tesfamariam et al. (2013) investigated the impact and interaction of soft story irregularities and construction quality on LCC of RC buildings under seismic hazard. Results of their analytical works showed that the impact of construction quality was of paramount importance in the overall LCC assessment.

Safi et al. (2015) provides insights into various aspects of bridges' LCC and illustrates analytical steps that transportation agencies could apply in bridge procurement. Their study shows that the use of design-build processes, together with the lowest life cycle cost bid as the contract award criterion, afford greater opportunities to 
consider LCC aspects in bridge procurement, rather than relying on traditional contracts and the lowest-bid criterion.

Introduced approaches to LCC analysis consider all costs incurred over the structure's life-time ranging from initial construction, to maintenance and repair, and to deconstruction. Difference and similarity of LCC estimation between three papers could be identified depending on their contexts.

\section{Conclusions}

This paper presents the most recently developments of fib Task Group 8.4 on existing LCC tools for concrete infrastructures. At this stage, authors are writing their chapters, being a resume of what is being done, provided above. The objective is to have all the chapters written, as well as a draft of the bulletin, within the next meeting, to be held in Maastrich, the Netherlands (just close to fib 2017).

\section{References}

ASTM E917-05, Standard Practice for Measuring Life-Cycle Cost of Buildings and Building Systems (2010)

Ellingham, I., Fawcett, W.: New Generation Whole-Life Costing. Property and Construction Decision Making Under Uncertainty. Taylor \& Francis, UK (2006)

EN 15643-4, Sustainability of Construction Works - Assessment of Buildings - Part 4: Framework for the Assessment of Economic Performance (2012)

EN 60300-3-3, Dependability management, Part 3-3: Life cycle costing analysis - Application guide (2005)

FHWA-IF-02-0047, Life-Cycle Cost Analysis Primer (2002)

FHWA-NJ-2003-012, Guidelines for Life Cycle Costs Analysis (2003)

fib Bulletin 71, Integrated life cycle assessment of concrete structures (2013). ISBN:978-2-88394-111-3

Frangopol, D.M., Kallen, M.J., Van-Noortwijk, J.M.: Probabilistic models for life-cycle performance of deteriorating structures: review and future directions. Prog. Struct. Mat. Eng. 6(4), 197-212 (2004)

ISO 55000, Asset management - Overview, principles and terminology (2014)

ISO 15686-5, Buildings and Constructed Assets Service Life Planning - Life Cycle Costing, 2008, Geneva, Switzerland (2008)

ISO 15868-5, Buildings and Constructed Assets Service Life Planning - Life Cycle Costing (2008)

Journal of Structural Engineering, vol. 142 (9) (2016)

Linneberg, P., Solgaard, A.O.S., Eriksen, K., Jensen, J.S.: Challenges within Life Cycle Cost (LCC) Studies and Life Cycle Assessment (LCA). In: Proceedings of the IABMAS 2014 (2014)

MAINLINE, MAINtenance, renewaL, and Improvement of rail transport iNfrastructure to reduce Economic and environmental impacts (2013). www.mainline-project.eu

Rackwitz, R.: Optimization-the basis of code making and reliability verification. Struct. Saf. 22 (1), 27-60 (2000) 
Safi, M., Sundquist, H., Karumi, R.: Cost-efficient procurement of bridge infrastructures by incorporating life-cycle cost analysis with bridge management systems. J. Bridge Eng. 20(6) (2015). 04014083-1-12

SAMPT, Structures Asset Management Planning Toolkit, Atkins (2015)

Tesfamariam, S., Sánchez-silva, M., Rajeev, P.: Effect of topology irregularities and construction quality on life-cycle cost of reinforced concrete buildings. J. Earthq. Eng. 17, 590-610 (2013)

The Green Book, The Green Book, Appraisal and Evaluation in Central Government, UK Govt, HM Treasury (2011)

Val, D.V., Stewart, M.G.: Life-cycle cost analysis of reinforced concrete structures in marine environments. Struct. Saf. 25, 343-362 (2003) 